\title{
Impacts of Cost Containment Strategies on Pharmaceutical Expenditures of the National Health Insurance in Taiwan, 1996-2003
}

\author{
Yue-Chune Lee, ${ }^{1}$ Ming-Chin Yang, ${ }^{2}$ Yu-Tung Huang, ${ }^{3}$ Chien-Hsiang Liu ${ }^{4}$ and Sun- \\ Bing Chen ${ }^{5}$ \\ 1 Institute of Health and Welfare Policy, College of Medicine, National Yang-Ming University, \\ Taipei, Taiwan \\ 2 Graduate Institute of Health Care Organization Administration, College of Public Health, \\ National Taiwan University, Taipei, Taiwan \\ 3 Division of Health Welfare Policy and Management, Institute of Public Health, College of \\ Medicine, National Yang-Ming University, Taipei, Taiwan \\ 4 Bureau of National Health Insurance, Taipei, Taiwan \\ 5 Division of Pharmaceutical Affairs, Bureau of National Health Insurance, Taipei, Taiwan
}

\section{Abstract}

Introduction: Pharmaceutical expenditure (PE) of the National Health Insurance (NHI) programme in Taiwan grew from 62.2 billion Taiwan new dollars (\$NT) in 1996 to \$NT94.5 billion in 2003.The government has been introducing many strategies to control PE since the inception of NHI including price adjustment based on the prices of international products or existing products (inter-brands comparison), or market price and volume survey; delegation of financial responsibility to regional bureaux; co-payment for outpatient drugs; generic grouping (the reference pricing scheme based on chemical equivalence); a global budget payment system for clinics and hospitals; and reduction in the flat daily payment rate of the drugs for clinics. The aim of this study was to evaluate the impact of these cost containment strategies on the PE of the NHI programme from 1996 to 2003. Methods: To take the growth and seasonal trends of monthly PE into consideration, Box and Tiao's time-series event intervention analysis based on the Box-Jenkins auto-regressive integrated moving-average model was applied to evaluate the impact of various cost containment strategies on total and subsector (outpatient, inpatient, clinic and hospital sectors) PE. Monthly data of PE of the NHI programme from 1996 to 2003 (the dependent variables) were obtained from the Bureau of the NHI. Drugs prescribed by dentists and Chinese medical doctors at outpatient departments were excluded.

Results: After fitting the patterns of time series and controlling for the calendar effect of the Chinese New Year and the severe acute respiratory syndrome outbreak in 2003, three strategies (generic grouping, delegation of financial responsibility and reduction of the flat payment rate of clinics) were significantly associated with a reduction in PE. However, the hospital global budget strategy 
offset partial savings from these three strategies. Cumulative savings during the study period were estimated to be \$NT25.442 billion (\$US0.80 billion). Of all the strategies, generic grouping was the most effective although it had less effect on the clinic subsector. Neither drug co-payment nor price adjustment based on the international or inter-brand price comparison had significant impacts on PE.

Conclusion: Generic grouping, reduction of the flat payment rate and delegation of financial responsibility were effective in controlling PE. A global budget alone would be unable to control PE without other direct financial incentives. Neither drug co-payment nor brand-specific price adjustment based on prices of international/existing products had a significant impact on PE.

National Health Insurance (NHI) in Taiwan, launched in 1995, offers comprehensive pharmaceutical benefits; in 2005 the formulary included about 16000 items of prescription drugs and about 1200 items of over-the-counter (OTC) drugs. Pharmaceutical expenditure (PE) grew from 62.2 billion Taiwan new dollars (\$NT) in 1996 to \$NT94.5 billion in 2003. Most pharmaceutical products are paid on a fee-for-services basis. Conflict of interests have arisen because hospitals and clinics are allowed to earn profits from the sale of pharmaceuticals, which are more profitable than that of medical services. Although there are no formal statistics, informal estimates suggest profits of 5-40\% for drugs and $<10 \%$ for services. Therefore, many physicians have a tendency to over-prescribe for their patients.

To reduce the financial incentives for over-prescribing and to control PE, the Bureau of National Health Insurance (BNHI), the sole payer, has been introducing many strategies over the last 10 years. These include reducing PE by adjusting pharmaceutical prices downwards and adjusting fee schedules of medical services upwards. ${ }^{[1,2]}$ Those reform strategies and when they were introduced are summarised in table I.

A Pharmaceutical Benefits \& Price List was first published in 1996, with a brand-specific price set for each product. To control costs on the demand side, the $\mathrm{BNHI}$ issues a list of positive and negative drugs that it does and does not cover. This list, which the $\mathrm{BNHI}$ has issued since its inception, limits the range of drugs prescribed. In addition, co-payment of outpatient drugs, initially introduced in August 1999, re-introduced a price to the patients to reduce excessive drug use because of moral hazard.

The supply-side regulations included price regulation, quantity regulation or both. Price regulation was the most commonly used strategy. Either price setting or freezing have been regularly applied to all drugs from 1996 onwards to reduce the payment price or to reduce the price variation/mark-up of drugs with the same ingredients. By 2003, price adjustment had been conducted six times, as shown in table II, and was based either on a comparison against international/existing products, a market survey/generic grouping, or flat payment rates.

The first two price adjustments (1996 and 1997), conducted by the BNHI, were based on international and inter-brands comparisons. Prices were used from other countries as a reference price for either patent-protected drugs or drugs listed by the Department of Health in Taiwan as under post-market surveillance. Prices of existing products were also used as a reference price for generic drugs (interbrands comparison).

Since 2000, a market price survey has been conducted regularly. The resulting weighted average price of each product has been the major reference for price adjustment thereafter. To further reduce price variation among off-patent drugs, 'generic grouping' or 'reference pricing' based on the similarity of active ingredients of the drugs was introduced in April 2001 and March 2003. Products of the same active ingredients were divided into two groups according to their quality: original brand and generic drugs proved to be comparable to the original brand on bio-availability and bio-equivalency 
Table I. Demand and supply-side drug cost containment strategies in Taiwan, 1995-2003

\begin{tabular}{|c|c|c|c|c|}
\hline \multirow[t]{2}{*}{ Strategies } & \multirow[t]{2}{*}{ Time $^{a}$} & \multicolumn{3}{|c|}{ Regulates } \\
\hline & & price & quantity & price and quantity \\
\hline \multicolumn{5}{|l|}{ Demand-side } \\
\hline Negative and positive list (formulary) & March 1995- & & $\checkmark$ & \\
\hline Drug co-payment & August 1999- & $\checkmark$ & & \\
\hline \multicolumn{5}{|l|}{ Supply-side } \\
\hline Price-setting/freeze: payment price & November 1996- & $\checkmark$ & & \\
\hline $\begin{array}{l}\text { Limit payment rate for clinics } \\
\text { (flat rate per day) - optional }\end{array}$ & March 1995- & & & $\checkmark$ \\
\hline \multicolumn{5}{|l|}{ Price adjustment } \\
\hline List price & 1996, 1997, 2000, 2001, 2003 & $\checkmark$ & & \\
\hline Flat payment rate & January 2002- & $\checkmark$ & & \\
\hline \multicolumn{5}{|l|}{ Global budget } \\
\hline Clinics & July 2001- & & & $\checkmark$ \\
\hline Hospitals & July 2002- & & & $\checkmark$ \\
\hline \multicolumn{5}{|l|}{ Management and utilisation control } \\
\hline Regional financial responsibility & May 1999-February 2001 & & $\checkmark$ & \\
\hline Utilisation review/profiling & March 1995- & & $\checkmark$ & \\
\hline Practice guideline & June 1995- & & $\checkmark$ & \\
\hline Auditing & March 1995- & $\checkmark$ & $\checkmark$ & \\
\hline
\end{tabular}

versus other generic products (Taiwan did not require bio-availability/bio-equivalence testing for all new generic products until 1993). For each group, the weighted average price was calculated and was set as the ceiling price of the products within that group.

To control the PE of clinics and allow physicians to keep the profit they used to enjoy from the sales of drugs before the inception of NHI, a flat rate of payment for pharmaceuticals per day (daily rate) was introduced in 1995 (\$NT35, \$NT70 and \$NT100 for 1, 2 and 3 days of prescription, respectively). However, it was not a mandatory regulation. Physicians could still file itemised claims if they wished, but they would be subject to utilisation review. The flat rate was reduced to $\$$ NT25 per day in January 2002, 6 months after the global budget system was introduced to the clinic sector. The savings from the reduction of flat rates were reallocated to raise physicians' consultation fees at clinics. A hospital global budget payment system (HGBPS) has been implemented since July 2002. However, except for the regular drug price adjustment applied to the hospitals and clinics sectors, no other direct incentive or control, similar to the reduction of flat payment rate of clinics, was introduced to control PE in the hospital sector.

To prevent providers from committing fraud on insurance claims, and to reduce inappropriate prescribing of drugs, certain management and utilisation control tools were also applied. These included the development of drug utilisation guidelines, auditing, providers' profiling (comparing the costs and patterns of prescriptions among the peer providers) and utilisation review. The 'delegation of financial responsibility' strategy, which delegated financial responsibility to six regional branches of the BNHI from May 1999 to February 2001 to enhance their financial accountability, is worth noting. Triggered by the first financial crisis of $\mathrm{NHI}$ in 1999 , financial responsibility encouraged regional bureaux to apply all cost containment tools available. This was fruitful in bringing down the total cost inflation and postponed the financial crisis until the time when the $\mathrm{BNHI}$ was finally able to raise the contribution rate of the payers on premiums in September 2002. The financial responsibility policy terminated in Februa- 
Table II. Reference price basis for the pharmaceutical price adjustments of the Taiwanese Bureau of National Health Insurance, 1996-2003

\begin{tabular}{|c|c|c|c|c|c|}
\hline \multirow{2}{*}{$\begin{array}{l}\text { Price adjustment } \\
\text { time }\end{array}$} & \multicolumn{4}{|l|}{ Reference price basis } & \multirow{2}{*}{$\begin{array}{l}\text { Number of items } \\
\text { adjusted }\end{array}$} \\
\hline & $\begin{array}{l}\text { international/existing product } \\
\text { (inter-brand competition) }\end{array}$ & $\begin{array}{l}\text { market price } \\
\text { survey }\end{array}$ & generic grouping & flat payment rate & \\
\hline November 1996 & $\checkmark$ & & & & 633 \\
\hline December 1997 & $\checkmark$ & & & & 710 \\
\hline April 2000 & $\checkmark$ & $\checkmark$ & & & 8961 \\
\hline April 2001 & $\checkmark$ & $\checkmark$ & $\checkmark$ & & 9801 \\
\hline January $2002^{a}$ & & & & $\checkmark$ & NA \\
\hline March 2003 & $\checkmark$ & $\checkmark$ & $\checkmark$ & & 8162 \\
\hline
\end{tabular}

a Flat payment rate adjustment.

NA $=$ not applicable.

ry 2001 when the then new president of the BNHI directed a change to new management goals.

Because many strategies, such as drug listing, price setting/freeze, utilisation review/auditing/ guidelines, have been applied since the inception or the early stage of NHI, we focused only on evaluating more recent interventions. These include drug co-payment for the demand side, price regulation, global budgets of clinics and hospitals and financial responsibility for the supply side. Due to a high coverage rate $(99 \%)$, the single-payer nature ${ }^{[1,3]}$ the complete claims data of pharmaceutical costs in all sectors and the various reform experiences during the past 10 years, ${ }^{[1,2,4]}$ we were able to evaluate and to compare the effects of multiple cost containment strategies on PE.

\section{Hypotheses and Rationales}

We hypothesised that: (a) generic grouping but not international and inter-brand price comparison would have had a significant impact on $\mathrm{PE}\left(\mathrm{H}_{1}\right)$; (b) without other direct financial incentives, global budgeting alone would not have controlled $\mathrm{PE}\left(\mathrm{H}_{2}\right)$; (c) outpatient drug co-payments would not have had a significant impact on $\mathrm{PE}\left(\mathrm{H}_{3}\right)$; and (d) reduction of flat payment rates for pharmaceutical costs of the clinics and delegation of financial responsibility would have had a significant impact on PE $\left(\mathrm{H}_{4}\right)$.

The rationale for these hypotheses, based on a literature review of economic theories and empirical studies, ${ }^{[5-8]}$ are described as follows.

For $\mathrm{H}_{1}$, previous studies showed that price control might fail because of an increase in volume or the substitution of other products not under priceregulation. ${ }^{[7,8]}$ The NHI price regulation based on international/inter-brand comparison set prices based on brand names, whereas generic grouping set ceiling prices for all brands of generic and patented drugs with the same ingredients. Since brand switching between generic and patented drugs would be relatively easier than chemical ingredient switching, we expected that generic grouping and not other price regulations would have an impact on PE.

For $\mathrm{H}_{2}$, under the global budget scheme, the money was allocated based mainly on fee-for-service. Therefore, without other direct incentives, providers would not change their prescribing behaviour. ${ }^{[8]}$

For $\mathrm{H}_{3}$, outpatient drug co-payments might affect patients' utilisation of drugs, ${ }^{[6]}$ but might not have a significant impact on PE because of information asymmetry and 'the supplier-induced demand' mechanism of the providers. ${ }^{[5]}$ Acting as an agent of their patients, physicians have no reason to change their existing prescribing patterns without direct financial incentives.

For $\mathrm{H}_{4}$, reduction of the flat payment rates was similar to a case-payment scheme (fixed payment), so the reduction of the rate of payment would have a significant impact on PE. Finally, the delegation of financial responsibility, introducing an approach like the new public management model, ${ }^{[9]} \mathrm{em}-$ phasised intra-public sector competition to improve local administrative capacities and autonomy. Local branches of the BNHI were encouraged to match 
local service need and to improve governance and efficiency. Hence we expected this strategy would be effective in reducing PE.

\section{Methods}

This study applied a 'quasi-experimental design' and used the time-series intervention methodology of Box and $\mathrm{Tiao}^{[10]}$ to examine the impacts of all cost containment strategies on the monthly PE of the NHI from 1996 to 2003. Box-Tiao's method determines the nature and magnitude of the changes due to certain policy interventions by comparing the change of a measure before and after that intervention. Because the monthly data are auto-correlated, i.e. any observation at 'time $t$ ' is correlated with the data in time $\mathrm{t}-1$ or $\mathrm{t}-2$, etc., the application of Box and Tiao's intervention model in this study took the growth and seasonal trend of monthly data into consideration, and analysed data based on the BoxJenkins auto-regressive integrated moving-average (ARIMA) model. ${ }^{[11]}$ The Box-Jenkins' ARIMA model assumes random measurement error in the dependent variables and produces unbiased estimates of the parameters that the traditional ordinal least square regression model may fail to achieve, due to the violation of random measurement error resulting from the analysis based on auto-correlated data.

\section{Model}

The functional form of the general intervention model is presented below:

$$
Y_{t}=a+\omega X_{t}+N_{t}
$$

where $Y_{t}$ is the value of the dependent variable at time $t, X_{t}$ stands for the policy intervention, $\omega$ is the size of the change in $Y_{t}$ associated with the intervention, and $N_{t}$ represents the noise component of the time-series model (Box-Jenkins' ARIMA model) at time $t$.

\section{Data Source and Measurement}

Monthly claims data for PE from 1996 to 2003, filed by all contracted clinics, hospitals and pharmacies, were obtained from the BNHI. Drugs pre- scribed by dentists and Chinese medical doctors at outpatient departments were excluded.

The dependent variable in this study was the nominal monthly PE. The nominal rather than the real PE was used in the analysis because the BNHI has not regularly adjusted prices, based on the pharmaceutical price index, of pharmaceutical products in Taiwan.

To represent the policy intervention and the time it was applied, a dummy variable $\left(\mathrm{X}_{\mathrm{it}}\right)$ was created for each ith cost containment strategy. For example, the dummy variable of regional financial responsibility equaled one during the period from May 1999 to February 2001, otherwise it equaled zero. The data at different points in time would reflect the kinds of strategies that had been introduced. It was possible to have multiple interventions at the same period of time.

In addition to the regular seasonal trends, the Chinese New Year, which usually last for 5-7 days according to the lunar calendar, was also expected to have a significant impact on PE expenditure. Therefore, we applied Liu's calendar intervention model, ${ }^{[12]}$ which introduced a variable to represent the Chinese New Year and control for this effect. Furthermore, as Chang et al. ${ }^{[13]}$ showed, there were $23.9 \%$ and $35.2 \%$ reductions in utilisation of ambulatory and inpatient care, respectively, during the outbreak of severe acute respiratory syndrome (SARS) in 2003. We therefore added a dummy variable to represent the SARS period from May to July 2003, to control for the impact of the outbreak of SARS on PE.

\section{Analyses}

To conduct ARIMA modeling, we first selected a tentative model for development. The model computed various permutations of the order of correlation, integration and moving average via an autocorrelations function and partial auto-correlation function. The model with the smallest mean square error was chosen to estimate the parameters (presented in the results). A t-test was applied to test whether the value of the estimated parameters were statistically different from zero. The prediction error 
was plotted to evaluate the validity of the model. Appropriate adjustment on the model was made if necessary. The Ljung-Box Q-statistic ${ }^{[11]}$ was used to test the lack-of-fit of the model.

Five models were estimated, including the total expenditure plus four subsector models, i.e. clinics, hospitals, outpatient and inpatient (both clinics and hospitals have outpatient/ambulatory and inpatient sectors in Taiwan). The costs claimed by pharmacies were traced back to either clinics or hospitals where the prescriptions came from. The analysis on clinics and hospitals reflects the performance of PE control at different global budget sectors. In addition, because the BNHI also has a policy to reduce outpatient costs (which accounted for two-third of total costs), the further analysis on inpatient and outpatient sectors allowed us to examine the nature and magnitude of the PE changes in response to different cost control strategies. All analyses were conducted using SPSS for Windows, version 11.5.

\section{Results}

Figure 1 presents the monthly total and subsector PE together with the cost containment strategies introduced by BNHI between 1996 and 2003. Significant non-stationary growing trends were found on total as well as on each sector of PE expenditure. Therefore, first order differences were applied in subsequent analyses to achieve stationarity in the ARIMA model.

Table III shows the annual total and subsector PE with growth rates. Total PE grew from \$NT62.2 billion in 1996 to $\$$ NT94.5 billion in 2003. The annual growth rates peaked during 1998-9 for total PE and almost all sectors, with a further peak in 2002 for the hospital/inpatient sector. By contrast, there was a major reduction of $9.6 \%$ for the clinic sector in 2002. Drugs prescribed by physicians at hospitals accounted for $64-73 \%$ of the total drug cost, whereas the clinic share of total PE expenditure declined over the study period. Since the inception of NHI, PE has accounted for a significant share (24.5-27.9\% during study period) of total NHI healthcare costs and percent of GDP (from $0.8 \%$ in 1997 to $1.0 \%$ in 2003).

Table IV presents the results of the intervention models of the time-series analyses. We tried to use $\log$ transformation of PE in the analyses to reflect the skew of the PE data. However, because the results were similar to the results without transformation, we only presented the model without transformation to make the interpretation of the coefficients easier. The coefficients of ARIMA models

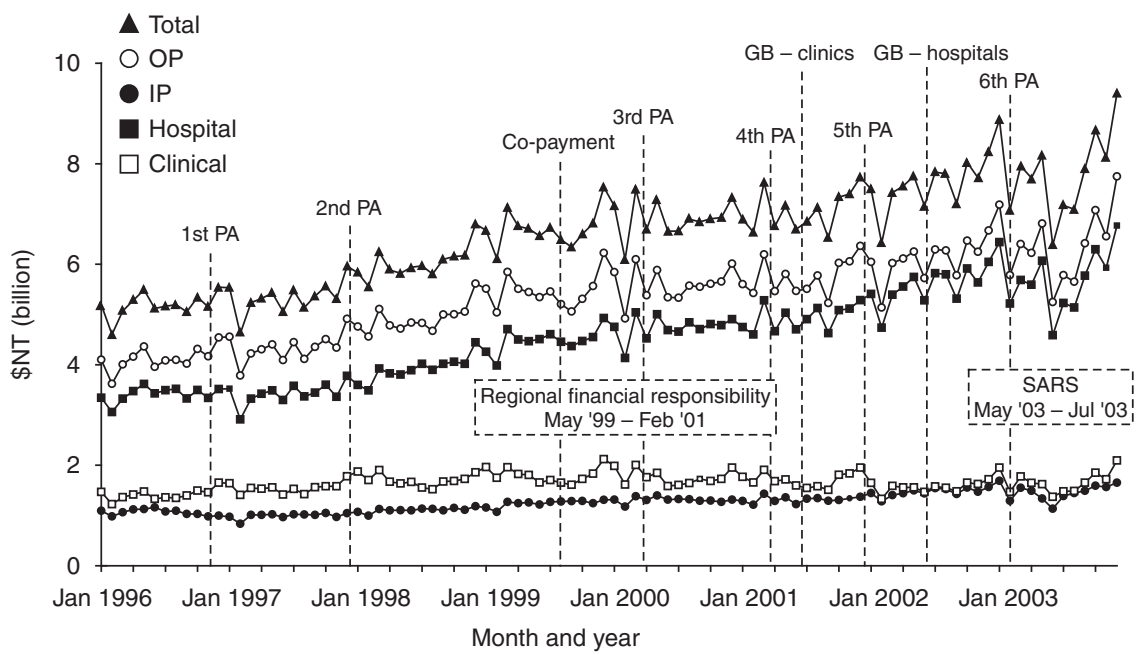

Fig. 1. Monthly total and subsector pharmaceutical expenditures (with no adjustment for inflation) of the Taiwan National Health Insurance, according to time of introduction of cost containment strategies, 1996-2003. \$NT = Taiwan new dollar; GB = global budget; IP = inpatient; OP = outpatient; PA = price adjustment; SARS = severe acute respiratory syndrome 
Table III. Annual pharmaceutical expenditures (PE) and growth rates of the Taiwanese National Health Insurance (NHI) programme, 1996-2003

\begin{tabular}{|c|c|c|c|c|c|c|c|}
\hline \multirow[t]{2}{*}{$\overline{\text { Year }}$} & \multicolumn{5}{|c|}{ Pharmaceutical expenditures [billion \$NT] ${ }^{a}$ (annual growth rates, \%) } & \multirow{2}{*}{$\begin{array}{l}\text { Total PE } \\
-(\% \text { GDP) }\end{array}$} & \multirow{2}{*}{$\begin{array}{l}\text { Total PE (\% NHI } \\
\text { expenditure) }\end{array}$} \\
\hline & outpatient & inpatient & hospitals & clinics & total $^{b}$ & & \\
\hline 1996 & 49.4 & 12.8 & 40.9 & 17.0 & 62.2 & 0.8 & 25.6 \\
\hline 1997 & $52.1(5.0)$ & $11.9(-6.9)$ & $41.1(0.4)$ & $18.6(8.4)$ & $64.0(2.8)$ & 0.8 & 24.5 \\
\hline 1998 & $58.9(11.7)$ & $13.3(10.3)$ & $47.0(12.5)$ & $20.5(9.3)$ & $72.3(11.4)$ & 0.8 & 24.8 \\
\hline 1999 & $65.5(10.0)$ & $14.9(10.6)$ & $53.8(12.7)$ & $21.6(5.2)$ & $80.4(10.1)$ & 0.9 & 25.4 \\
\hline 2000 & $67.2(2.5)$ & $15.7(5.3)$ & $56.9(5.3)$ & $21.2(-2.1)$ & $82.9(3.0)$ & 0.9 & 25.3 \\
\hline 2001 & $68.9(2.5)$ & $15.8(0.5)$ & $59.2(3.9)$ & $20.6(-2.8)$ & $84.7(2.1)$ & 0.9 & 25.1 \\
\hline 2002 & $73.0(5.6)$ & $17.6(10.2)$ & $66.7(11.2)$ & $18.8(-9.6)$ & $90.6(6.5)$ & 0.9 & 25.1 \\
\hline 2003 & $76.9(5.0)$ & $17.6(0.2)$ & $68.7(3.0)$ & $20.1(6.8)$ & $94.5(4.1)$ & 1.0 & 27.9 \\
\hline \multicolumn{8}{|c|}{ a $\quad$ \$US1 = \$NT32 in 2005. Prices were not adjusted for inflation. } \\
\hline \multicolumn{8}{|c|}{ b Total = inpatient + outpatient. } \\
\hline \multicolumn{8}{|c|}{ \$NT = Taiwan new dollar. } \\
\hline
\end{tabular}

associated with each cost containment strategy indicated the monthly impacts of a specific strategy on a specific sector. After fitting the patterns of time series and controlling for the calendar effect of the Chinese New Year and the SARS outbreak in 2003, three strategies (generic grouping, delegation of regional financial responsibility and reduction of flat payment rates for clinics) had significant $(\mathrm{p}<0.05$, t-test) negative coefficients (i.e. reduction of costs) in either total or subsector models. Price adjustment based on either international or inter-brand price comparison or on market price survey had no significant effects on PE. Neither did outpatient drug copayments and a global budget for the clinic sector $(\mathrm{p}>0.05)$. These results were consistent with our hypotheses. In addition, a hospital global budget increased PE significantly, as expected $(\mathrm{p}<0.05)$.

Of all the strategies, generic grouping had the most significant impact on reducing all PE except for the clinic sector. A major source of savings resulted from the hospital outpatient sector on both the fourth and the sixth price adjustment, when generic grouping was introduced, and also from the inpatient sector on the fourth price adjustment. The reduction of the flat payment rate of the clinics had significant impact on the PE of the clinics and outpatient sectors while the delegation of regional financial responsibility had a significant impact on the inpatient sector. However, the latter had no significant impact on overall PE. All the models passed the lack-of-fit tests using Ljung-Box Q-statistics. $^{[11]}$

Table V shows that the 'annual' and 'cumulative savings' of each cost containment strategy proved to have significant impacts on PE during the study period. The total cumulative net savings from all cost containment strategies were \$NT25.442 billion. Generic grouping (April 2001 and March 2003) and reduction of flat drug payment rate (January 2002) accounted for \$NT25.371 (20.114 + 5.257) billion and \$NT10.128 billion savings, respectively. Regional financial responsibility was associated with a reduction of \$NT1.261 billion on the PE of the inpatient sector during the study period. However, the savings mentioned above were somewhat offset by an increase in the hospital global budget of \$NT10.057 billion. The overall savings, in general, were greater from the outpatient than from the inpatient sector, and more from hospitals than clinics. The same trends were also identified from analyses of annual savings, which examined the average annual effect of a cost containment strategy on PE during the year it was introduced.

\section{Discussion}

Since the inception of the NHI, Taiwan has applied price regulation on pharmaceutical products to control PE. The other purpose of the adjustment was to capture the benefits from market forces or the bargaining power of the hospitals and clinics. Our 
Table IV. Impacts of containment strategies on monthly pharmaceutical cost (\$NT $\times$ billion; $\$$ US1 $=\$ N T 32$ in 2005) of the Taiwanese National Health Insurance programme, 1996-2003: time-series intervention analysis

\begin{tabular}{|c|c|c|c|c|c|}
\hline \multirow[t]{2}{*}{ Event variables } & \multicolumn{5}{|l|}{ Models } \\
\hline & total & outpatient & inpatient & clinics & hospitals \\
\hline First PA - international and inter-brands price comparison & 0.015 & 0.037 & -0.004 & 0.050 & -0.040 \\
\hline Second PA - international and inter-brands price comparison & 0.228 & 0.168 & 0.060 & 0.119 & 0.119 \\
\hline Regional financial responsibility & -0.203 & -0.159 & $-0.057^{\star}$ & -0.046 & -0.161 \\
\hline Outpatient drugs co-payment & -0.306 & -0.349 & NA & -0.082 & -0.179 \\
\hline Third PA - market price survey & -0.218 & -0.198 & -0.040 & -0.059 & -0.170 \\
\hline Fourth PA - market survey and generic grouping & $-0.610^{*}$ & $-0.502^{*}$ & $-0.120^{\star}$ & -0.131 & $-0.483^{*}$ \\
\hline Global budget payment system for clinics & 0.222 & 0.147 & NA & -0.081 & NA \\
\hline Fifth PA - flat payment rates & $-0.422^{*}$ & $-0.467^{*}$ & NA & $-0.364^{*}$ & NA \\
\hline Global budget payment system for hospitals & $0.559^{*}$ & $0.485^{*}$ & 0.008 & NA & $0.314^{*}$ \\
\hline Sixth PA - market survey and generic grouping & $-0.526^{\star}$ & $-0.479^{\star}$ & -0.005 & -0.049 & $-0.464^{\star}$ \\
\hline Chinese New Year & $-0.435^{*}$ & $-0.379^{*}$ & $-0.048^{*}$ & $-0.105^{*}$ & $-0.290^{*}$ \\
\hline SARS outbreak period (from May to July 2003) & $-0.706^{*}$ & $-0.411^{*}$ & $-0.256^{\star}$ & $-0.137^{*}$ & $-0.464^{*}$ \\
\hline \multicolumn{6}{|l|}{ ARIMA model ${ }^{\mathrm{a}}$} \\
\hline$(p, d, q)^{b}-$ time-series pattern & $(2,1,0)$ & $(2,1,0)$ & $(1,1,0)$ & $(1,1,0)$ & $(2,1,0)$ \\
\hline$(P, D, Q) 12$ - seasonal time-series pattern & $(1,0,0)$ & $(1,0,0)$ & $(1,0,0)$ & $(1,0,0)$ & $(1,0,0)$ \\
\hline Constant & 0.056 & 0.053 & 0.003 & 0.014 & 0.043 \\
\hline First order correlation, $\mathrm{AR}(1)$ & $-0.767^{*}$ & $-0.707^{\star}$ & $-0.629^{*}$ & $-0.518^{*}$ & $-0.746^{\star}$ \\
\hline Second order correlation, $\mathrm{AR}(2)$ & $-0.202^{*}$ & $-0.197^{\star}$ & NA & NA & $-0.191^{\star}$ \\
\hline Seasonal first order correlation, SAR(1) & $0.749^{*}$ & $0.722^{*}$ & $0.745^{\star}$ & $0.662^{*}$ & $0.715^{\star}$ \\
\hline
\end{tabular}

a Auto-regressive (AR) order.

b Used 12 months as a seasonal factor to reflect that the data had a yearly cycle.

\$NT = Taiwan new dollar; ARIMA = auto-regressive integrated moving-average $\mathbf{d}=$ differencing order; $\mathbf{D}=$ seasonal differencing order; $\mathbf{N A}=$ not applicable; $\mathbf{p}=$ order of correlation; $\mathbf{P}=$ seasonal order of correlation; $\mathbf{P A}=$ price adjustment; $\mathbf{q}=$ moving average; $\mathbf{Q}=$ seasonal moving average; $\mathbf{S A R}=$ seasonal auto-regressive; $\mathbf{S A R S}=$ severe acute respiratory syndrome; ${ }^{\star} p<0.05$. 
Table V. Estimated annual and cumulative effects of pharmaceutical cost (NT $\times$ billion; $\$$ US1 $=\$ N T 32$ in 2005) containment strategies on pharmaceutical expenditures (PE) of the Taiwanese Natinoal Health Insurance programme, 1996-2003a

\begin{tabular}{|c|c|c|c|c|c|}
\hline \multirow[t]{2}{*}{ Event variables } & \multicolumn{5}{|l|}{ Models } \\
\hline & total & outpatient & inpatient & clinics & hospitals \\
\hline \multicolumn{6}{|l|}{ Annual savings } \\
\hline regional financial responsibility & & & -0.057 & & \\
\hline fourth PA - market survey and generic grouping & -0.610 & -0.502 & -0.120 & & -0.483 \\
\hline \multicolumn{6}{|l|}{ global budget payment system for clinics } \\
\hline fifth PA - flat payment rates & -0.422 & -0.467 & & -0.364 & \\
\hline global budget payment system for hospitals & 0.559 & 0.485 & & & 0.314 \\
\hline sixth PA - market survey and generic grouping & -0.526 & -0.479 & & & -0.464 \\
\hline Chinese New Year & -0.435 & -0.379 & -0.048 & -0.105 & -0.290 \\
\hline SARS outbreak period (from May to July 2003) & -0.706 & -0.411 & -0.256 & -0.137 & -0.464 \\
\hline \multicolumn{6}{|l|}{ Cumulative saving during study period (1996-2003) } \\
\hline regional financial responsibility & & & -1.261 & & \\
\hline fourth PA - market survey and generic grouping & -20.114 & -16.556 & -3.967 & & -15.949 \\
\hline \multicolumn{6}{|l|}{ global budget payment system for clinics } \\
\hline fifth PA - flat payment rates & -10.128 & -11.206 & & -8.746 & \\
\hline global budget payment system for hospitals & 10.057 & 8.735 & & & 5.650 \\
\hline sixth PA - market survey and generic grouping & -5.257 & -4.794 & & & -4.642 \\
\hline Chinese New Year & -2.119 & -1.232 & -0.767 & -0.411 & -1.394 \\
\hline SARS outbreak period (from May to July 2003 & -3.483 & -3.034 & -0.386 & -0.838 & -2.319 \\
\hline Total saving & -25.442 & -23.820 & -5.227 & -8.746 & -14.941 \\
\hline
\end{tabular}

a Impacts were calculated only for the strategies which had significant impacts on PE.

$\mathbf{P A}=$ price adjustment; $\mathbf{S A R S}=$ severe acute respiratory syndrome. 
study, as expected, only found significant effects on PE for price adjustment based on generic grouping; other price-cut strategies based on reference prices of either international, existing products or from a market price survey all failed to control costs. Although the international reference price might actually bring the prices down for single-source patented products, the real impact might not be significant due to relatively higher prices of the reference countries, which were all developed countries and all had higher per capita GDP than that of Taiwan. Huang et al. ${ }^{[14]}$ found that in Taiwan $35 \%$ of original-brand drugs had prices higher than those in the US and Australia in 1996.

For multiple-source products, price cuts on certain products might only result in market redistribution. ${ }^{[8]}$ Besides, previous payment incentives for providers in Taiwan, in general, were to encourage them to maximise profit margins rather than to buy the cheapest or the most cost-effective products. Therefore, the providers usually responded quickly by replacing products under price regulation with those that were either exempted from price cuts (because of different dosages, packages or forms but the same ingredients) or still allowed the providers to enjoy high profit margins. ${ }^{[7,8]}$ In addition, by increasing the volume of the pharmaceuticals prescribed (by number of prescriptions, durations or daily doses) [supplier-induced demand] ${ }^{[5]}$ or by asking vendors to offer the same level of profits before the price-cut (cost-shifting), healthcare providers were always the winners. Therefore, little savings would be expected from a brand-specific price cut, especially with minor price reductions and on only a few products.

Generic grouping, on the contrary, was quite significant in reducing PE because: (a) it targeted products that were off-patent, had been on the market for more than 25 years (in 2001) or 22 years (in 2003), and had very high sales (> \$NT100 million per year), so the room for price cuts were high; (b) ceiling prices were introduced and calculated based on the weighted average price of subgroups of products rather than on individual brands, so the price differences among products of the same ingredients were greatly reduced; and (c) price regulation applied to all-brands of similar products, thereby making it difficult to switch to other more profitable products with similar pharmacological ingredients or therapeutic effects.

The generic grouping strategy in Taiwan shared some similarity with the maximum allowable cost of the Medicaid programs in the US ${ }^{[15]}$ and the reference price system which Germany pioneered. The reference price system in Germany paid ceiling payment prices for clusters of drugs which were defined according to rules of chemical equivalence (same active ingredient), pharmacological equivalence or therapeutic equivalence. ${ }^{[7,8,16,17]}$ Patients were allowed to pay for the difference above the reference price. The generic grouping strategy in Taiwan also set a ceiling price based on chemical equivalence but allowed no balance billing. Giuliani et al., ${ }^{[17]}$ in evaluating the reference price scheme of Germany, found the reference price to be very effective in controlling 'price' but possibly not as effective in controlling 'costs' in the long-run due to the subsequent increase in volumes. Similar results were also noted by the review done by Kanavos and Reinhardt ${ }^{[16]}$ They also found no empirical evidence suggesting that the reference price reduces total system costs. Therefore, Taiwan should monitor the effect of generic grouping carefully in the future.

In addition, our study also found that the reduction of the flat payment rate of drugs was associated with a significant reduction of PE for clinics. The flat rate payment was just like the case payment scheme without case-mix adjustment. Physicians practicing at clinics favoured the flat rate because it allowed them to keep profits and be exempted from any financial penalties resulting from utilisation review. After the implementation of the global budget reform for clinics, which covered physicians' services as well as drug costs, the Taiwan Medical Association (on behalf of the clinics) decided to reduce the flat rate and use the savings to raise physician consultation fees. In essence, this leads to budget reallocation and a minor reduction in the number of prescriptions and has no real savings in total costs, as observed in our analysis. 
The effect of the HGBPS, which also set a national expenditure cap on all the hospitals, was totally different. Our study found that the HGBPS actually increased PE by $\$ N T 10.057$ billion rather than reducing it. There were several explanations.

Hospitals' pharmaceuticals are paid by fee-forservices; no flat rates are available. Second, under the HGBPS, there is a strong financial incentive for 'individual' hospitals to increase the costs of drugs to compensate for their loss of income from reduced payments for medical services. Third, in addition to the increase in drug prescriptions, hospitals also increased volumes of outpatient and inpatient services, which also accounted for part of the increase in PE. Similar experiences were also found in Germany. The regional drug budgeting scheme was abolished in Germany because of the resistance of physicians to take fiscal responsibility for overspending on the drug budget. ${ }^{[18]}$ However, the UK was able to achieve a lower increase in PE by setting a drug budget or by allowing GPs to hold prescription drug budgets, enhancing their responsibility. ${ }^{[18,19]}$ Therefore, direct incentives should be tailored to individual physicians to achieve actual cost savings if a global budget scheme is to be effective.

Our study found that the delegation of financial responsibility to regional bureaux significantly reduced PE for the inpatient sector only. The effect of financial responsibility might have been due to the introduction of 'pseudo-competition' among regional bureaux following the new public management model. ${ }^{[9]}$ As a result of the competition among regional bureaux, numerous strategies have been developed by regional bureaux, including the extensive use of physician and patient profiling, providers' special investigation, persuasion and advice, case management for frequent users, etc. The reason that financial responsibility failed at the outpatient sector was not clear. One possible explanation might be that an outpatient drug co-payment was also introduced around the same time. It would be difficult to differentiate the effects of both policies in our time-series intervention analysis.

Liu and Romeis ${ }^{[20]}$ also evaluated the use of outpatient drug co-payments in reducing pharma- ceutical costs using a pre-test post-test controlled group experimental design, but limited the sample to the elderly in 21 hospitals at Taipei city. Their result also showed that an outpatient drug co-payment failed to reverse the trend of prescription drug cost increases. The failure of drug co-payments in controlling drug expenditures might be because (a) the amount of co-payment was too low (\$NT20-200 per visit); (b) the ceiling for drug co-payment was too low (\$NT200); (c) many patients were exempt from drug co-payment; or (d) there was no direct policy to enhance financial responsibility of physicians who were the ones prescribing the drugs. As mentioned in the hypotheses and rationales section, drug copayments might reduce patient-physician contacts. However, due to the agency role of the providers and the 'supplier induced demand' mechanism, physicians might not change their prescribing behaviour without payment incentives.

\section{Study Limitations}

The application of time-series event intervention analysis and the control on the effects of Chinese New Year and the SARS outbreak in this study enable us to take the growth and seasonal trends and some external events into consideration. However, our study still has the following limitations:

1. None of the interventions evaluated in this study was evaluated via a randomised control trial. Most cost containment strategies were introduced without any control groups because of the single-payer nature of our insurance system. These design features might pose threats to internal validity.

2. Although we took all possible system-wide interventions and the SARS outbreak into consideration, we failed to control for other external minor changes such as changes in guidelines and utilisation review policies. This might have also threatened the internal validity of our analysis.

3. Our analysis might not be sensitive enough to differentiate the effects of multiple interventions that were introduced around the same time.

4. The NHI programme in Taiwan is a single-payer system with fee-for-service as the predominant unit of payment, with hospitals operating under a closed- 
staff model. So the implications of this study might be different from country to country.

\section{Conclusions}

Since the NHI programme was launched, Taiwan has introduced a variety of cost containment strategies, including various price regulations, co-payments and a global budget payment system. Our study confirmed the hypotheses that generic grouping (the reference price scheme based on chemical equivalence) and the reduction of the flat (fixed) payment rate for drugs were associated with a significant reduction in PE. Delegation of financial responsibility to regional bureaux also had a significant impact on PE in the inpatient sector. Brandspecific price-cuts, based either on international prices, existing prices or on market price, all failed to control PE. We also found that providers in different sectors, i.e. clinic versus hospitals, responded differently to a global budget payment system.

\section{Acknowledgements}

Y.-C. Lee and M.-C. Yang were responsible for the study design, the supervision on data analysis, the interpretation of the results and preparation of the manuscript. Y.-T. Huang was responsible for the data analysis and in drafting the manuscript on the methodological section. C.-H. Liu supervised the database preparation and interpretation of the results. S.-B. Chen prepared the monthly cost database from the original claim data.

This study is self-funded. C.-H. Lui is president and CEO of the BNHI and S.-B. Chen is employed by the BNHI, Division of Pharmaceutical Affairs. The authors have no other conflicts of interest to declare.

We deeply appreciate the Bureau of National Health Insurance for providing research data.

\section{References}

1. Cheng TM. Taiwan's new national health insurance program: genesis and experience so far. Health Aff 2003; 22 (3): 61-76

2. Huang WF, Chiang HC. Pharmaceutical benefit scheme and cost containment in Taiwan's National Health Insurance. J Pharm Finance Econ Policy 2003; 12 (2): 133-49

3. Chiang TL. Taiwan's 1995 health care reform. Health Policy 1997; 39 (3): 225-39
4. Lu JFR, Hsiao WC. Does Universal health insurance make health care unaffordable? Lessons from Taiwan. Health Aff 2003; 22 (3): 77-88

5. McGuire TG. Physician agency. In: Culyer AJ, Newhouse JP, editors. Handbook of health economics. New York: Elsevier, 2000: 461-536

6. Zweifel P, Manning WG. Moral hazard and consumer incentives in health care. In: Culyer AJ, Newhouse JP, editors. Handbook of health economics. New York: Elsevier, 2000: 409-60

7. Dickson M. Paying for prescriptions in Europe. In: OECD: Health policy studies no. 4. Health: quality and choice. Paris: OECD, 1994: 83-109

8. Ess SM, Schneeweiss S, Szucs TD. European healthcare policies for controlling drug expenditure. Pharmacoeconomics 2003; 21 (2): 89-103

9. Saltman R, Bankauskaite V, Vrangbaek K. Decentralization in health care: strategies and outcomes [online]. Available from URL: http://www.who.dk/observatory/Studies/ 20031112_1.htm [Accessed 2005 Feb 23]

10. Box GEP, Taio GC. Intervention analysis with applications to economic and environmental problems. J Am Stat Assoc 1975; 70 (349): 70-9

11. Box GEP, Jenkins GM, Reinsel GC. Time series analysis: forecasting and control. 3rd ed. Upper Saddle River (NJ): Prentice Hall, 1994

12. Liu LM. Analysis of time series with calendar effects. Manage Sci 1980; 26 (1): 106-12

13. Chang HJ, Huang N, Lee CH, et al. The impact of the SARS epidemic on the utilization of medical services: SARS and the fear of SARS. Am J Public Health 2004; 94 (4): 562-4

14. Huang WF, Lo KL, Chen LW. Comparison of Taiwan's NHI drug price and international drug price [in Chinese]. Chin J Public Health 1998; 17 (3): 265-72

15. Abramson R, Harrington CA, Missmar R, et al. Generic drug cost containment in Medicaid: lessons from five state MAC programs. Health Care Financ Rev 2004; 25 (3): 25-34

16. Kanavos P, Reinhardt U. Reference pricing for drugs: is it compatible with US health care? Health Aff 2003; 22 (3): 16-30

17. Giuliani F, Selke G, Garattini L. The German experience in reference pricing. Health Policy 1998; 44 (1): 73-85

18. Delnoij D, Brenner G. Importing budget systems from other countries: what can we learn from the German drug budget and British GP fundholding? Health Policy 2000; 52 (3): 157-69

19. Harris CM, Scrivener G. Fundholders' prescribing costs: the first five years. BMJ 1996; 313 (7071): 1531-4

20. Liu SZ, Romeis JC. Changes in drug utilization following the outpatient prescription drug cost-sharing program-evidence from Taiwan's elderly. Health Policy 2004; 68 (3): 277-87

Correspondence and offprints: Dr Yue-Chune Lee, Institute of Health and Welfare Policy, National Yang-Ming University, No.155, Sec. 2, Linong Street, Taipei, Taiwan 112, ROC. E-mail: yclee@ym.edu.tw 